\title{
Metal stent impaction in scope channel successfully rescued by argon plasma coagulation with double scope method
}

An 89-year-old woman with a history of malignant biliary obstruction caused by unresectable intraductal papillary mucinous carcinoma (IPMC) was admitted for cholangitis due to plastic stent occlusion, which had been inserted for the ingrowth occlusion of a covered self-expandable metal stent (CSEMS) ( $>$ Fig. 1).

We planned to remove the plastic stent and insert another CSEMS through the existing CSEMS. Duodenoscopy (TJF 260V; Olympus, Tokyo, Japan) revealed a large quantity of mucus from IPMC, which was difficult to remove and gain clear visibility in the second part of duodenum ( Fig. 2).

We attempted to withdraw the plastic stent using grasping forceps through the scope channel. However, we inadvertently grasped the mesh of the CSEMS together with the plastic stent and retracted them together into the scope channel. The stents became impacted in the channel and could not be pulled or pushed out with forceps.

We then inserted an ultra-thin endoscope (GIF N290; Olympus) alongside the duodenoscope, and both scopes were positioned and stretched out ( $\triangleright$ Fig. 3 ).

The ultrathin endoscope revealed the impacted CSEMS between the duodenoscope and the papilla. Transection by argon plasma coagulation (APC) was successfully performed all around the CSEMS by both straight and inverted positioning of the ultrathin endoscope ( $\triangleright$ Fig.4, Video 1). Finally, we were able to withdraw the plastic stent and the CSEMS fragment through the endoscope, and insert a new CSEMS ( $>$ Fig. 5). Metal stent impaction in the scope channel is a rare and dreadful adverse event. Above all, we have to pay attention to the careful removal of the plastic stent, especially when visibility is poor. In this video case report, we described metal stent impaction salvaged by APC transection using a double scope method [1].

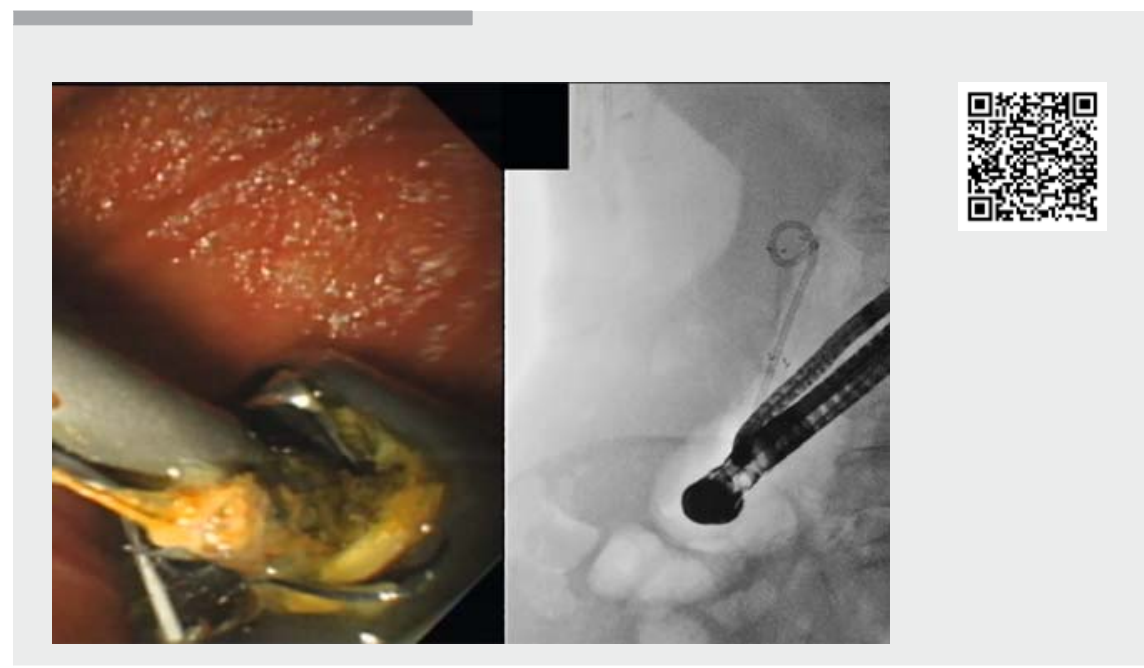

$\checkmark$ Video 1 Metal stent impaction in the scope channel was successfully rescued by argon plasma coagulation using the double scope method.
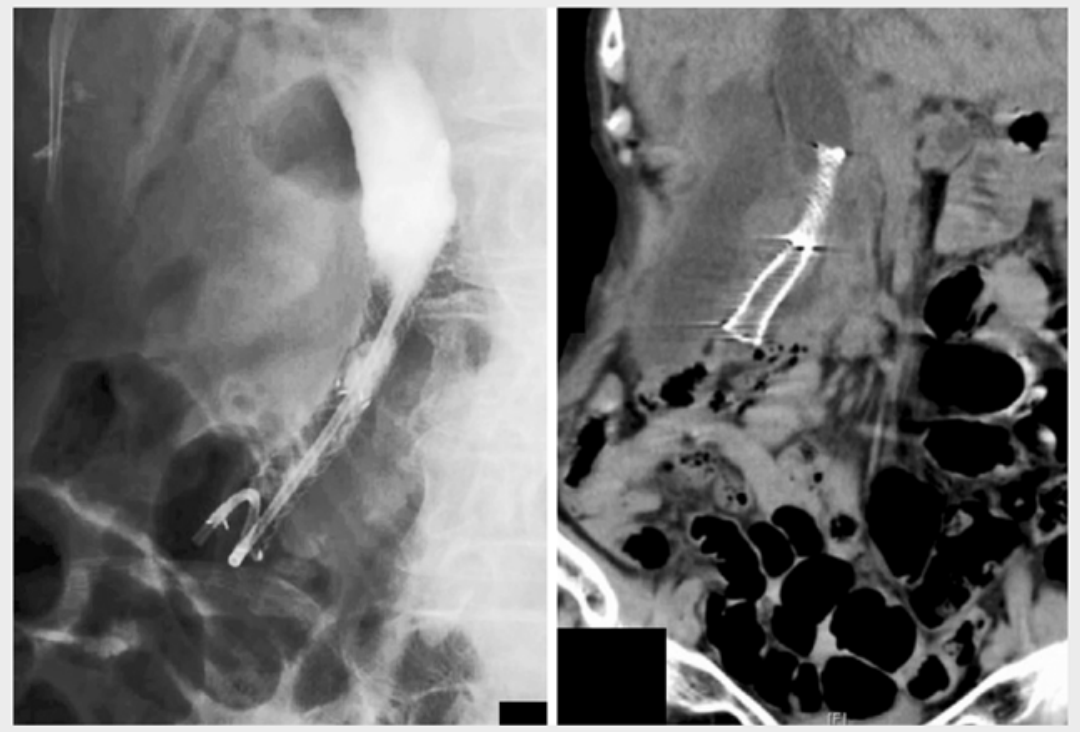

- Fig. 1 A plastic stent was inserted for ingrowth occlusion of a covered self-expandable metal stent.

The double scope method has been reported for endoscopic submucosal dissection $[2,3]$. This is the first report of the combination of duodenoscope and ultrathin endoscope, which may be useful in other biliopancreatic procedures.

Endoscopy_UCTN_Code_CPL_1AK_2AD 


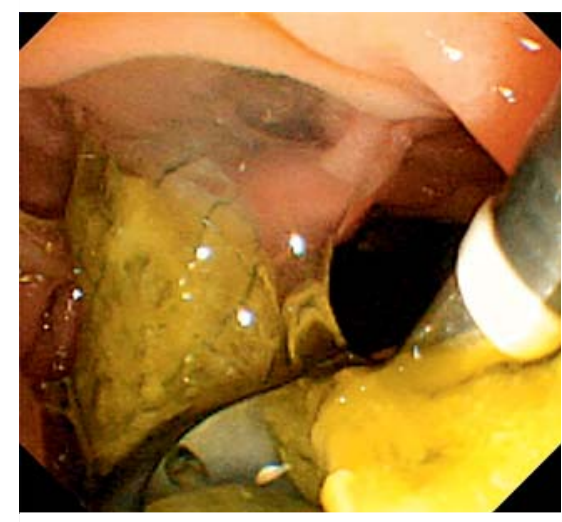

- Fig. 2 A large quantity of mucus from the intraductal papillary mucinous carcinoma prevented clear visibility.

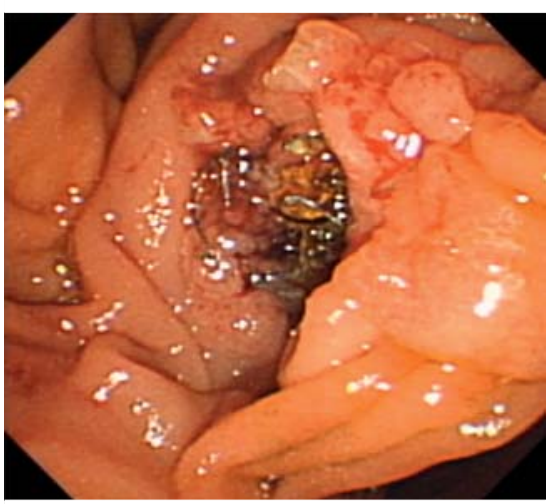

- Fig. 4 Transection by argon plasma coagulation was successfully performed all around the self-expandable metal stent.

\section{Competing interests}

None

The authors

Koji Nagaike ${ }^{1}$, Shiro Hayashi ${ }^{2}$, Yuichi Satomoto $^{3}$, Hirokazu Sasakawa ${ }^{1}$, Kengo Nagai ${ }^{1}$, Yuichi Yoshida ${ }^{1}$, Masafumi Naito ${ }^{1}$

1 Department of Gastroenterology and Hepatology, Suita Municipal Hospital, Osaka, Japan

2 Division of Gastroenterology and Internal Medicine, Hayashi Clinic, Osaka, Japan

3 Department of Gastroenterology and Hepatology, Osaka University Graduate School of Medicine, Osaka, Japan
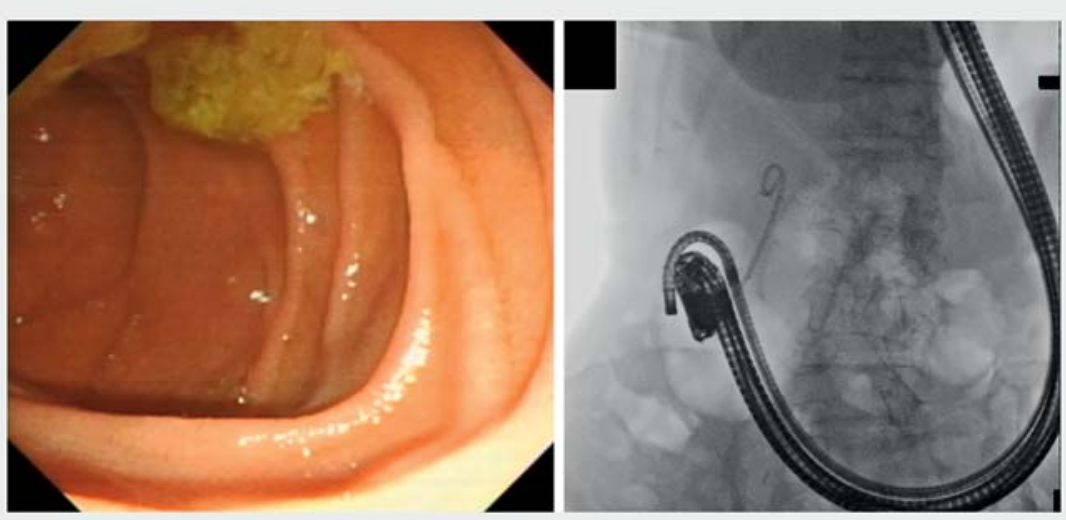

Fig.3 An ultrathin endoscope was inserted alongside the duodenoscope.

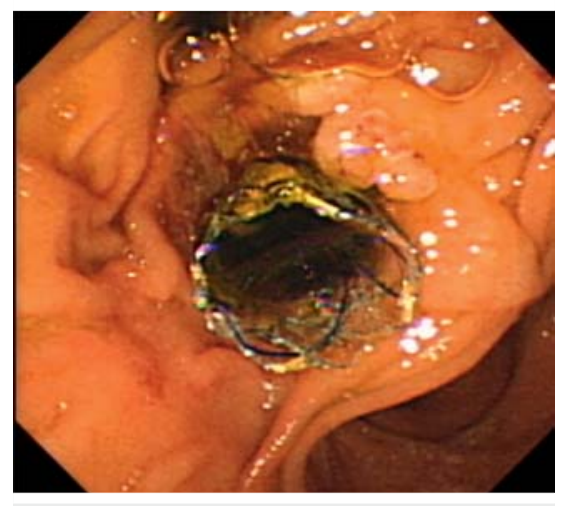

- Fig. 5 A new covered self-expandable metal stent was placed.

\section{Corresponding author}

\section{Koji Nagaike, MD}

Department of Gastroenterology and

Hepatology, Suita Municipal Hospital,

5-7 Kishibeshinmachi, Suita,

Osaka 564-8567, Japan

Fax: +81-6-63805825

nagaike.koji@gmail.com

\section{References}

[1] Ishii K, Itoi T, Sofuni A et al. Endoscopic removal and trimming of distal self-expandable metallic biliary stents. World J Gastroenterol 2011; 17: 2652-2657
[2] Higuchi K, Tanabe S, Azuma M et al. Doubleendoscope endoscopic submucosal dissection for the treatment of early gastric cancer accompanied by an ulcer scar (with video). Gastrointest Endosc 2013; 78: 266-273

[3] Oterdoom LH, Goet JC, Jacobs MA et al. UItra-thin caliber endoscopes in daily practice: uses for therapeutic application and beyond on the basis of review of 1028 procedures. Endosc Int Open 2015; 3: E400-404

\section{Bibliography}

DOI https://doi.org/10.1055/a-0977-2357

Published online: 21.8.2019

Endoscopy 2020; 52: E27-E28

(c) Georg Thieme Verlag KG

Stuttgart · New York

ISSN 0013-726X

\section{ENDOSCOPY E-VIDEOS}

https://eref.thieme.de/e-videos

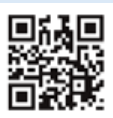

Endoscopy E-Videos is a free access online section, reporting on interesting cases and new techniques in gastroenterological endoscopy. All papers include a high quality video and all contributions are freely accessible online.

This section has its own submission website at

https://mc.manuscriptcentral.com/e-videos 